\title{
A new species of Trichogenes from the rio Itapemirim drainage, southeastern Brazil, with comments on the monophyly of the genus (Siluriformes: Trichomycteridae)
}

\author{
Mário C. C. de Pinna ${ }^{1}$, José Luiz Helmer ${ }^{2}$, Heraldo A. Britski ${ }^{1}$ \\ and Leandro Rodrigues Nunes ${ }^{2}$
}

\begin{abstract}
A new species of the formerly monotypic genus Trichogenes is described from a high-altitude stream of the rio Itapemirim system, an isolated Atlantic drainage in the State of Espírito Santo, southeastern Brazil. Trichogenes claviger, new species, differs from all other trichomycterids by the sexually dimorphic posterior process of the opercle, much elongated in males; the terminal mouth; the deeply bifurcated anterior neural spines and the presence of a large anterodorsal claw-like process on the neural arches of the anterior four free vertebrae. The new species also differs from its only congener, T. longipinnis, by a number of additional traits, including the the lack of branched anal-fin rays in specimens of any size; the broader than long posterior nostril; the deeper head (head depth 72.9-86.6\% HL); the presence of a fine dark line along the base of the anal fin; the lack of dark spots on cheeks; the shape of the interopercle; the presence of odontodes on a bony expansion on the posterodorsal margin of the interopercle; the fewer vertebrae (35); the absence of an antorbital; and the fewer pleural ribs (eight). Small juveniles of the new species are also strikingly different from those of all other Trichomycteridae, including T. longipinnis, having a very large lateral eye, an upturned mouth, and compressed head. Trichogenes claviger occurs in shaded sectors of a blackwater sluggish stream with sandy substrate and patchy accumulations of vegetable debris, a habitat markedly different from the rocky torrential environment known for T. longipinnis. A comparison of the internal anatomy of the two species provides the basis for a hypothesis of a monophyletic Trichogenes. Data from the new species further support a sister-group relationship between Trichogeninae and Copionodontinae, as well as the position of that clade as sister group to all remaining Trichomycteridae.
\end{abstract}

Uma espécie nova do gênero previamente monotípico Trichogenes é descrita de um riacho de altitude pertencente à drenagem do rio Itapemirim, uma bacia Atlântica isolada do Estado do Espírito Santo, sudeste do Brasil. Trichogenes claviger, espécie nova, difere de todos os outros Trichomycteridae pela presença sexualmente dimórfica de um processo posterior do opérculo muito alongado nos machos; a boca terminal; os espinhos neurais das vértebras anteriores profundamente bifurcados; e a presença de um grande processo em forma de garra ântero-dorsalmente nos arcos neurais das quatro primeiras vértebras livres. A espécie nova também se diferencia de seu único congenérico, T. longipinnis, por várias outras características, incluindo: a ausência de raios ramificados na nadadeira anal em exemplares de todos os tamanhos; a narina posterior mais larga que longa; a cabeça mais alta (altura da cabeça 72,9-86,6\% do seu comprimento); a presença de uma fina linha negra ao longo da base da nadadeira anal; a ausência de manchas negras na face lateral da cabeça; o formato distinto do interopérculo; a presença de odontódeos em uma expansão óssea na margem posterodorsal do interopérculo; o menor número de vértebras (35); a ausência de antorbital; e o menor número de costelas pleurais (oito). Exemplares jovens da espécie nova são notavelmente diferentes daqueles de todos os outros Trichomycteridae, incluindo T. longipinnis, tendo um olho muito grande em posição lateral, a boca inclinada para cima e a cabeça comprimida. Trichogenes claviger ocorre em setores sombreados de um riacho de água preta, de correnteza lenta, com substrato arenoso e aglomerações de matéria vegetal em alguns pontos, um habitat bastante diferente do ambiente rochoso e torrencial de T. longipinnis. Uma comparação da anatomia interna das duas espécies fornece a base para uma hipótese de monofiletismo de Trichogenes. Dados da espécie nova corroboram a hipótese de grupo-irmão entre Trichogeninae e Copionodontinae, assim como a posição deste clado como grupo-irmão de todos os restantes Trichomycteridae.

Key words: Taxonomy, Systematics, Juvenile fish, Biodiversity.

\footnotetext{
${ }^{1}$ Museu de Zoologia da Universidade de São Paulo. Av. Nazaré 481, 04263-000 São Paulo, SP, Brazil. pinna@ib.usp.br ${ }^{2}$ Universidade Federal do Espírito Santo, Depto de Biologia. Av. Marechal Campos 1468, 29040-090 Vitória, ES, Brazil.
} 


\section{Introduction}

Trichogenes longipinnis was described as a new genus and species by Britski \& Ortega (1983). The highly conspicuous fish, markedly distinctive from all the rest of the neotropical freshwater fish fauna, was a surprising discovery in an area of Atlantic rainforest between two of the most populous urban centers in South America (Rio de Janeiro and São Paulo). Trichogenes is particularly interesting in displaying plesiomorphic character conditions previously unknown in the family. Its combination of character states has had considerable impact on the understanding of the phylogeny and evolution of loricarioid catfishes (de Pinna, 1992; Stiassny \& de Pinna, 1994). Although existing populations of $T$. longipinnis at the moment seem to be healthy, they occur only in a few vulnerable isolated coastal streams, spanning a maximum of $10 \mathrm{~km}$, and the species obviously needs special protection (Sazima, 2004, 2008). Recent studies on genetic diversity have revealed high populational structure in the species, an unexpected phenomenon for a taxon with such a tiny geographical range (Zamudio et al., 2009).

For many years, $T$. longipinnis was considered to be a unique relict, without any close relatives. Despite extensive ichthyological exploration in coastal drainages of southeastern Brazil over the past 25 years, no other species of the genus was ever encountered. Also, no populations of the species have been found outside of the immediate neighborhood of the type locality. The taxon closest to Trichogenes is the subfamily Copionodontinae (de Pinna, 1992, 1998; Bichuette et al., 2008; Datovo \& Bockmann, 2010), a rather distinct relictual group of fishes endemic to the Chapada Diamantina, an isolated plateau in the northeastern Brazilian State of Bahia, drained by the headwaters of the rio Paraguaçu and ca. $1200 \mathrm{~km}$ distant in straight line from the known range of $T$. longipinnis.

In this paper, we report on a second species of Trichogenes unexpectedly discovered during biological inventory activities in the Forno Grande farm, State of Espírito Santo, southeastern Brazil. The species was found in a tributary to the headwaters of the rio Itapemirim drainage, an isolated Atlantic basin. While clearly related to $T$. longipinnis, the new species differs from it in several traits of external and internal anatomy, as well as in the morphology of juveniles. Some ecological differences also seem to exist. The new species is a substantial addition to lower trichomycterid diversity. It breaks the long phylogenetic branch previously separating $T$. longipinnis from other trichomycterids, and will contribute to a clearer understanding of the evolution of the group.

\section{Material and Methods}

Pectoral-, pelvic-, dorsal- and anal-fin ray counts include a value for anterior unbranched segmented rays represented in Roman, and the branched segmented ones in Arabic numerals, separated by a comma. Procurrent rays are defined as all unsegmented raylike elements anterior to the main finray series (composed of segmented rays, branched or unbranched), and their number is indicated separately. The two posterior closely-set rays in dorsal and anal fins, when present, are counted separately. Principal caudal-fin rays include all branched elements plus one unbranched ray in each lobe, with counts for each lobe (dorsal first) separated by a plus sign. Vertebral counts do not include those in the compound Weberian centrum and the compound caudal centrum (PU1+U1) is counted as one. Vertebral counts and position of pterygiophore insertion were based on digital radiographs and cleared and stained specimens. Branchiostegal rays and procurrent fin rays were counted on cleared and stained preparations only. Odontode counts include only odontodes that are attached to bone, or in the process of replacing an already detached odontode, or an obviously empty socket which happens to have lost both its occupant and replacement.

All measurements are straight line, taken with digital calipers on the left side of specimens whenever possible and recorded to the nearest $0.1 \mathrm{~mm}$. Definitions of measurements follow Tchernavin (1944) and de Pinna (1992), except for head length (HL). Traditional measurements of HL as applied to the new species, would result in distorted proportional readings because of the pronounced elongation of the posterior portion of the opercle in males. Therefore, HL was measured from the anteriormost medial point of upper jaw to the dorsalmost exposed point of the branchial membrane, immediately ventral to the posterior opercular process. It is expected that this point is approximately positionally homologous with the one normally used to measure HL in other trichomycterids.

Specimens were cleared and counterstained for bone and cartilage according to a modified version of the methods of Taylor \& van Dyke (1985) and Song \& Parenti (1995). Sexing of specimens was based on direct examination of gonads, exposed by a small incision in the abdominal wall, slightly anterior to vertical through base of pelvic fin, on the right side of specimens. Abbreviations are: c\&s (cleared and stained preparation); MBML (Museu de Biologia Mello Leitão, Santa Teresa, Brazil); and MZUSP (Museu de Zoologia da Universidade de São Paulo, São Paulo, Brazil).

\section{Trichogenes claviger, new species Figs. 1a, 2a, 3a, 4, 5, 6a, 6b}

Holotype. MBML 3289, $50.8 \mathrm{~mm}$ SL, Brazil, State of Espírito Santo, Municipality of Castelo, córrego Picada Comprida (tributary, in sequence, to ribeirão Braço Sul, rio Caxixe and rio Castelo), rio Itapemirim drainage, $20^{\circ} 30$ '43”S 41 01 '59”'W, 15 Feb 2010, J. L. Helmer \& L. R. Nunes.

Paratypes. Total of 17 specimens, all collected with holotype. MBML 3290, 11 (1 c\&s), 15.9-44.4 mm SL; MZUSP 105732, 6 (2 c\&s), 22.7-40.0 mm SL. 
Diagnosis. Three autapomorphies unique among Trichomycteridae distinguish $T$. claviger from all other members of the family: the sexually dimorphic posterior process of the opercle, much elongated in males (Fig. 2; vs. short in both males and females); the terminal mouth (Fig. 1; vs. subterminal or inferior); and the presence of an anterodorsal claw-like process on the dorsal surface of the neural arch of each of the anterior four free vertebrae (Fig. 3a). Further distinguished from its only congener, T. longipinnis, by several additional characteristics (some of which may also be autapomorphic, pending more detailed analysis): the shape of the interopercle, with odontodes extending onto the posterodorsal margin of the interopercle on a bony expansion; (Fig. 4; vs. odontodes mostly restricted to ventral and posterior margins of the bone); the posterior naris broader than long ( vs. round); the presence of an entirely differentiated fleshy lobe laterally on the lower lip ( $v s$. fleshy lobe mostly continuous with the lower lip); the lack of branched anal-fin rays in specimens of any size ( $v s$. most anal-fin rays branched in specimens over $41 \mathrm{~mm} \mathrm{SL}$ ); the less deep caudal peduncle (9.3-11.5 vs. 10.3-12.6\% SL); the deeper head (head depth 72.9-86.6 vs. 50.3-62.8\% HL); the absence of an antorbital (vs. plate-like antorbital present dorsally to antorbital process of lateral ethmoid); the deep coronoid process of the lower jaw (Fig. 5; vs. coronoid process approximately one-third less deep); the flattened bifurcated tooth cusps, with roundish margins (Fig. 5; vs. bifurcated tooth cusps conical, pointed); the presence of 35 vertebrae ( $v s .38$ or 39 ); the presence of 6 branchiostegal rays ( $v s .7)$; the absence of a pelvic splint ( $v s$. pelvic splint present); the presence of 8 pleural ribs (vs. 10 or 11); the few sparse dark spots on body (Fig. 1; vs. spots more numerous and more densely arranged); the well-defined thin dark line along base of anal fin, formed by a regular row of slanted elongate spots on the distal portion of each pterygiophore (Fig. 1; vs. no such line); the lack of dark spots on the sides of head (Fig. 1; vs. lateral surfaces of head with roundish spots); the dark spots on body not extending onto base of caudal fin (Fig. 1; vs. spots covering bases of principal caudal-fin rays). The body shape of $T$. claviger, with the deepest part of the body at the middle of the abdomen, then continuously less deep posteriorly to the base of the caudal fin, and the dorsal and ventral profiles of the head forming broad symmetrical arcs with the body profile, result in a rather different general aspect when compared to $T$. longipinnis. In the latter, the deepest part of the body is at the origin of the anal fin, and the body depth is approximately even along its entire length, only slightly decreasing towards the caudal fin. Also, the dorsal and ventral profiles of the head and body are not symmetrical, with the former gently convex and the latter approximately straight.

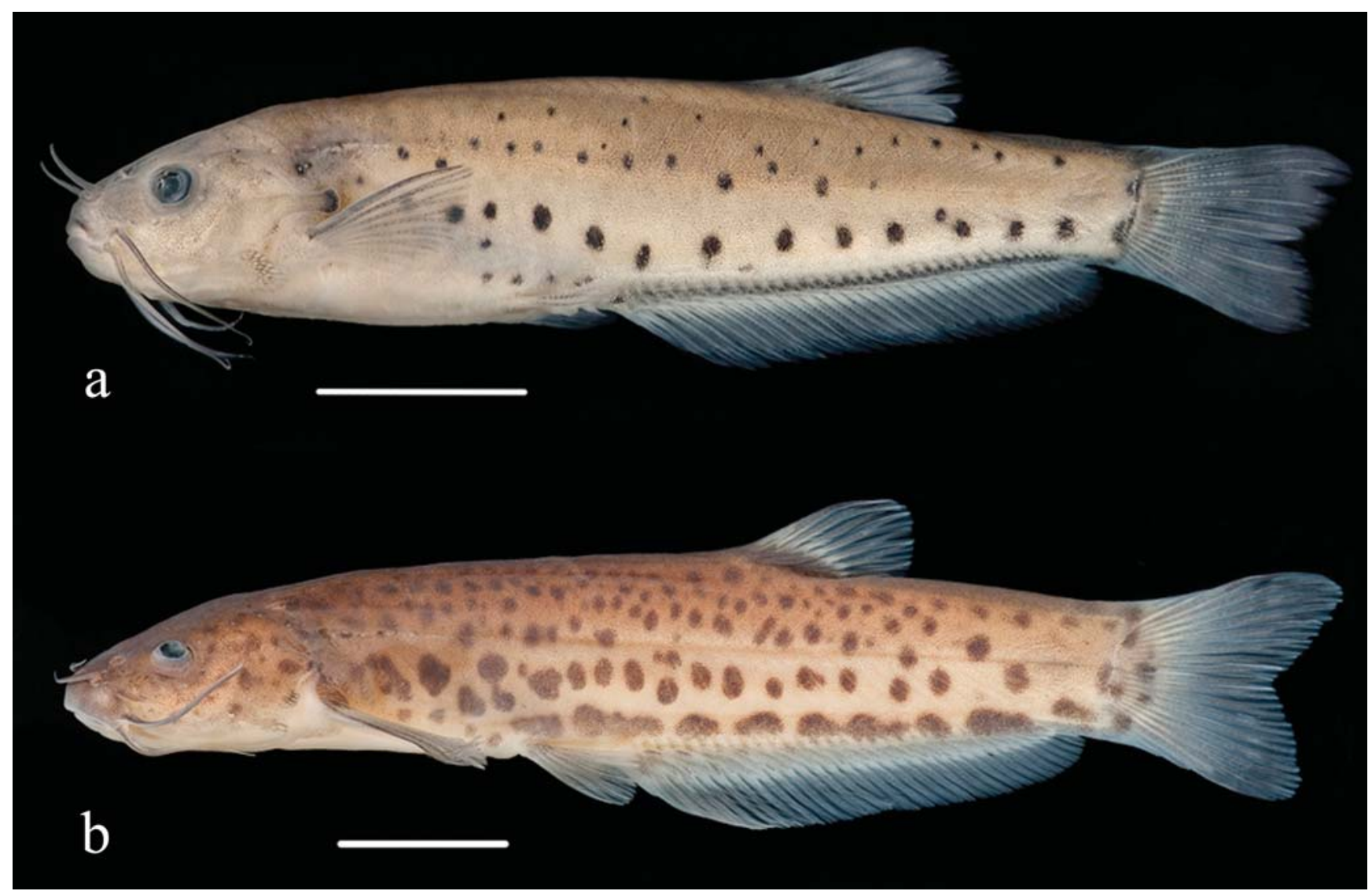

Fig. 1. Lateral views of species of Trichogenes. a) T. claviger, new species, MBML 3289, holotype, 50.8 mm SL; b) T. longipinnis, MZUSP 83452, $65.2 \mathrm{~mm}$ SL. Scale bars $=10 \mathrm{~mm}$. Photos by V. Barão. 
Description. Morphometric data given in Table 1. Body blunt, deeper than broad anteriorly and gradually more compressed posteriorly to caudal fin. Anterior part of body and head, from snout to dorsal-fin origin, in broad continuous convex arc. Dorsal profile of posterior region of body, from endpoint of dorsal fin to caudal-fin origin, mostly straight. Ventral profile broadly convex from snout to origin of pelvic fins, then straight along entire length of anal-fin base. Deepest part of body at middle of abdomen, then gradually less deep to base of caudal fin.

Head wide and deep, its depth approximately threequarters or more of HL. Mouth terminal, positioned at middepth of head, with jaws equally long or sometimes either upper or lower jaw slightly longer. Upper and lower lips narrow. Upper lip continuous laterally with maxillary barbel. Lower lip smaller and narrower than upper lip, subdivided into welldefined elongate fleshy lobe laterally, separating lip from base of rictal barbel. Dentary teeth 19-23, disposed in two rows. Outer row with 7 or 8 large, distally expanded, compressed and slightly tan-colored, bilobed teeth, with round cusp

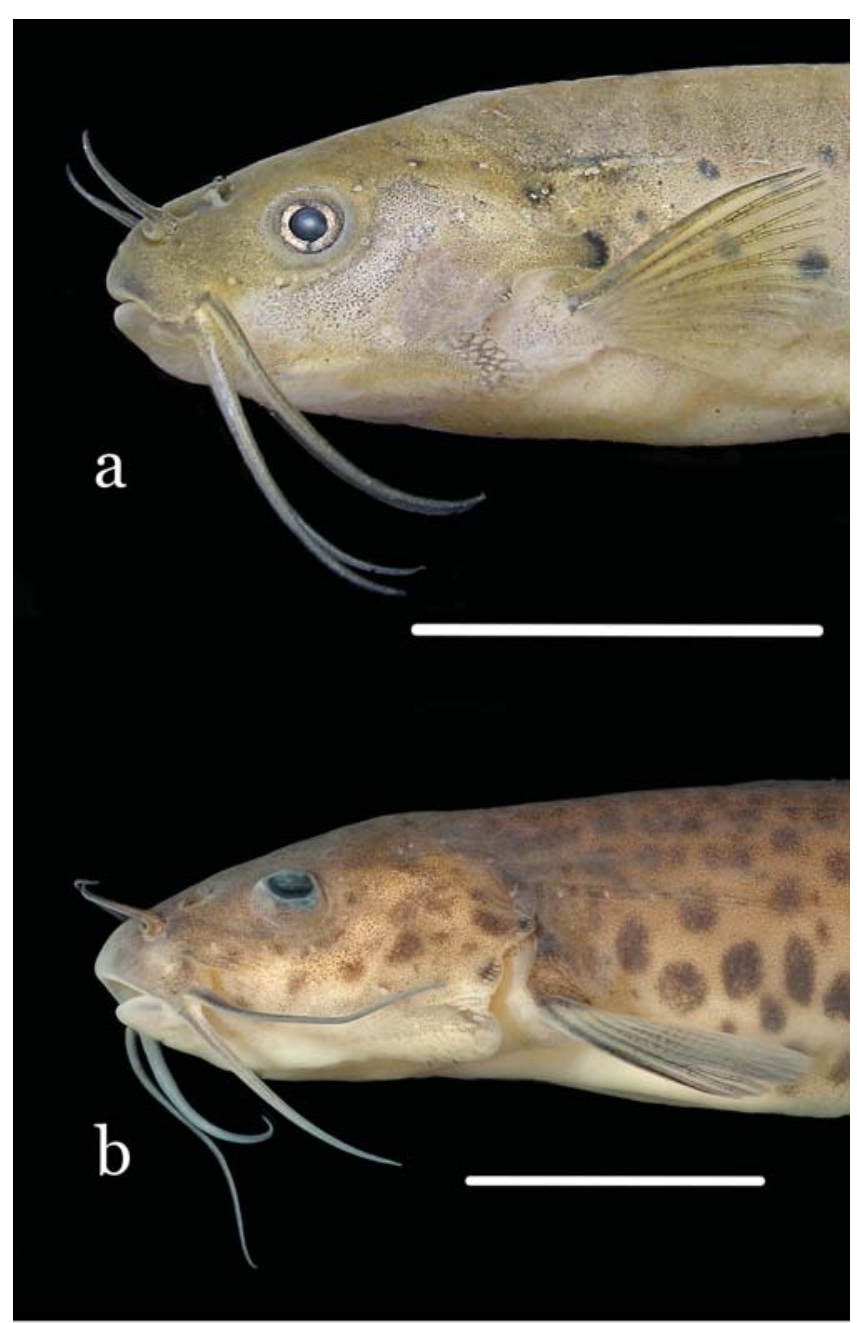

Fig. 2. Lateral views of head of species of Trichogenes. a) $T$. claviger, MBML 3289, holotype, $50.8 \mathrm{~mm} \mathrm{SL}$, immediately after preservation; b) T. longipinnis, MZUSP 83452, 65.2 mm SL. Scale bars $=10 \mathrm{~mm}$. Photos by: J. L. Helmer (a), and V. Barão (b). edges, gradually smaller laterally. Teeth on inner row smaller, less markedly expanded and less deeply bilobed than on outer one. Two rows mixing up laterally, with 2-4 lateral teeth conical. Premaxillary teeth similar to those on dentary, 20-22 in number and also disposed in two rows, with 6-8 teeth in outer row. Difference in tooth morphology between rows similar to that described for dentary. Two or three lateralmost premaxillary teeth of inner row conical. Many replacement tooth cusps alongside inner tooth row on both dentary and premaxilla.

Center of eye located slightly anterior to middle of HL, closer to lateral margin of head than to dorsal midline in dorsal view. Skin over eye thin and transparent, orbital margin free. Infraorbital latero-sensory canal complete, with five ossicles plus well-ossified lacrimal anteriorly. Five infraorbital pores, first one positioned posterodorsally to eye, second one posteroventrally to it, third and fourth ones along ventral margin of eye and fifth one directly anterior to that. Anterior naris surrounded by short anterolateral integument tube, continuous posterolaterally with nasal barbel. Posterior naris large and wide, broader than long in shape, located directly posterior to anterior one and partly occluded by two partly continuous flaps of skin. Three pairs of barbels, maxillary one maximally reaching base of first pectoral-fin ray. Rictal barbel inserted ventrally to maxillary
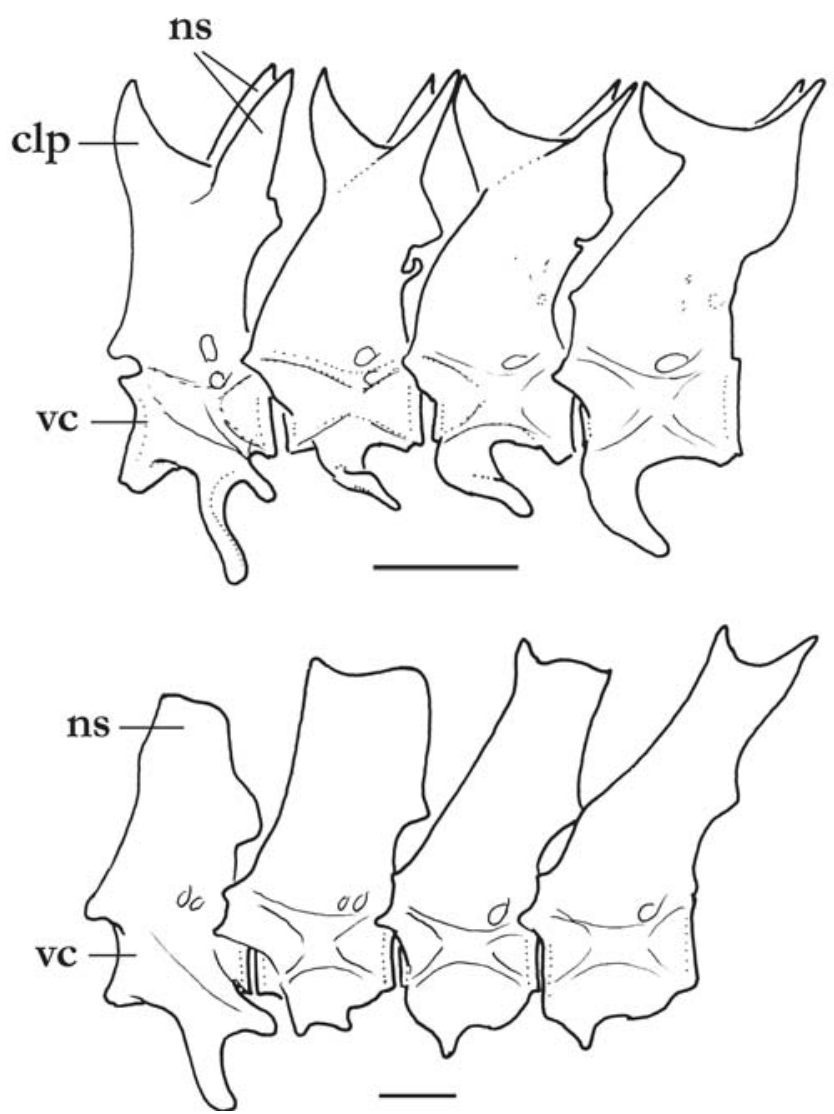

Fig. 3. Anterior four free vertebrae in Trichogenes, anterior to left. a) T. claviger, MZUSP 105732, paratype; b) T. longipinnis, MZUSP 48108. clp (claw-like process), ns (neural spine), and vc (vertebral centrum). Scale bars $=10 \mathrm{~mm} \mathrm{SL}$. 
one, reaching posterior tip of interopercular patch of odontodes. Nasal barbel originating on posterolateral region of anterior naris, reaching anterior margin of eye. Opercular odontodes disposed in two separate groups (Fig. 6). Dorsal group with 11-13 small odontodes in large specimens (5 or 6 in small specimens) at distal portion of well-defined opercular process with round expanded tip. Size of opercular process variable among specimens, and positiveallometrically related to body size and probably sexually dimorphic (see Discussion). Second small patch of opercular odontodes located anteroventrally to opercular process, bearing 2-5 tiny odontodes (one paratype entirely lacking second patch of odontodes on one side). Interopercle with well-developed patch of odontodes, visible in lateral and ventral aspect of head. Odontodes extending onto dorsal margin of bone, rendering its exposed, odontode-bearing, portion leaf-shaped. Interopercular odontodes 20-30, arranged in two series, main one extending alongside edge of interopercle, with large odontodes oriented obliquely to ventral margin of bone (Fig. 4). Smaller series less orderly disposed, wih small odontodes interspersed among bases of large odontodes on main row. Odontodes extending onto posterodorsal portion of interopercle, forming well-defined roundish saw-like arrangement of erect small odontodes on prominent bone expansion (Fig. 4). Interopercular odontodes less numerous in small individuals (13 in specimen $37.6 \mathrm{~mm} \mathrm{SL}$ ).

Pectoral fin large, with convex distal profile, its base immediately posterior to vertical through tip of interopercle, shorter than HL. Pectoral-fin rays i,9 $(n=9)$ or i, $10(n=1)$, and some specimens with asymmetrical counts ( $n=7$, holotype). Pelvic fin with round distal profile, its origin slightly posterior to vertical through tip of pectoral fin. Pelvic-fin rays i,5 $(n=2)$ or i,6 ( $n=11)$, and some specimens with those values differing on each side ( $n=3$; holotype), and single specimen with i,7 on one side and i,6 on the other. First pelvic-fin ray (unbranched) shorter than others. Pelvic splint absent. Dorsal fin smaller than anal and pectoral fins, its dorsal profile convex. Dorsal-fin origin closer to base of caudal fin than to tip of snout. Dorsal-fin rays i,7, plus single large procurrent ray anteriorly. Anal fin long, its distal profile straight or gently

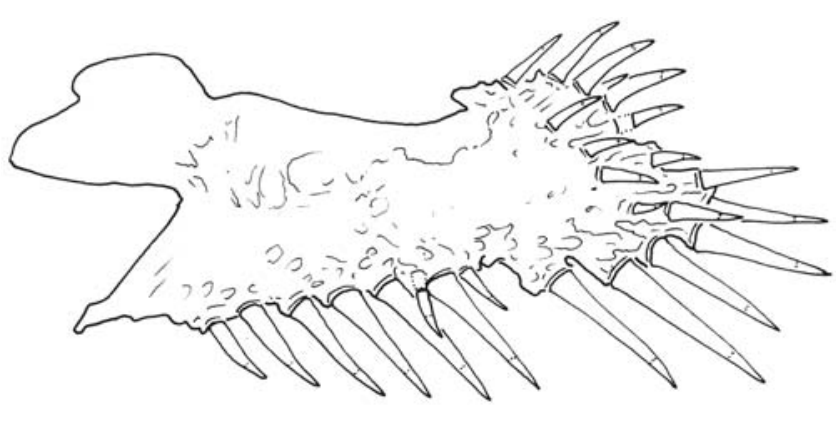

Fig. 4. Interopercle of Trichogenes claviger, lateral view, left side; MZUSP 105732, paratype. Scale bar $=1 \mathrm{~mm}$. convex, with round posterior end. Last anal-fin ray adnate between $30-80 \%$ of its length. Origin of anal fin slightly anterior to middle of SL, its base longer than $50 \%$ of body length (excluding head). Anal-fin origin located slightly anterior to middle of SL. All anal-fin rays unbranched (except for single $6^{\text {th }}$ ray branched in one specimen), numbering $32(\mathrm{n}=3), 33(\mathrm{n}$ $=8), 34(\mathrm{n}=5$; holotype $)$ or $35(\mathrm{n}=1)$, plus 2 small procurrent rays. Caudal fin bilobed, with $7+8$ principal rays. Upper lobe slightly longer than lower lobe in some specimens. Procurrent caudal-fin rays 9 or 10 dorsally and 6 or 7 ventrally.

Lateral line short, extending from posterior part of head almost to vertical through margin of pectoral fin, composed of an interrupted series of 4 or 5 short independent tubules, with small pore at each extremity. Each lateral-line segment with one delicate lateral-line ossicle, progressively less wellcalcified posteriorly. Vertebrae $35(\mathrm{n}=16)$. First anal-fin pterygiophore inserted posterior to haemal spine of 10 th free vertebra $(n=12)$. First dorsal-fin pterygiophore inserted posterior to neural spine of $16^{\text {th }}$ free vertebra $(n=11)$. Dorsalfin pterygiophores 8 , anal-fin pterygiophores 32 or 33 (holotype). Pleural ribs 8 , sometimes with small additional vestige posteriorly. Branchiostegal rays 6 .

Coloration. Sides of body with scattered dark round or oval spots of different sizes, roughly small, medium and large (Fig. 1a). Largest and most conspicuous of such spots forming a series ( 9 to 13 in number) beginning posteriorly to opercular process and continuing obliquely ventrally to near the origin of the anal fin, then extending approximately in parallel to anal-fin base until end of caudal peduncle. Additional round markings scattered sparsely on sides of body, medium-sized ones concentrated near midline and smaller ones mostly on dorsal half of sides, not forming any specific pattern and mostly or entirely absent on dorsum. Dark spots of all sizes less numerous in small specimens, and totally absent in uniform dark grey smallest individual ( $15.9 \mathrm{~mm} \mathrm{SL})$. Some adult specimens showing only main row of large spots, lacking small and medium-sized ones. Dark spots not entering base of caudal fin. Entire body, except abdomen, with fine uniform background covering of small melanophores, abruptly denser dorsal to lateral midline and slightly denser along limits of

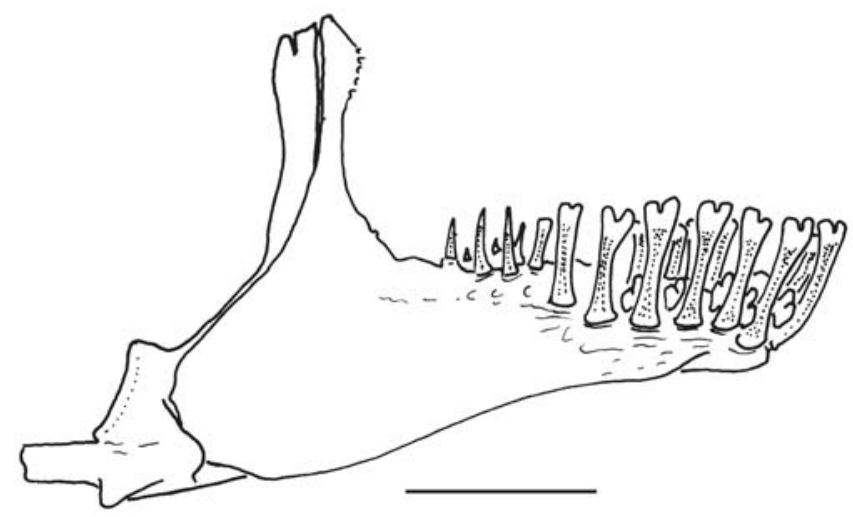

Fig. 5. Dentary of Trichogenes claviger, lateral view, right side; MZUSP 105732, paratype. Scale bar $=1 \mathrm{~mm}$. 
myosepta and on dorsal midline. Abdominal region white, except for narrow dark fields between bases of pelvic fins and a dense concentration anterior to origin of anal fin. Anterior portion of lateral line with amorphous dark cloud and small dark spot around one or two anterior pores. A well-defined dark line on body along base of anal fin, formed by series of partly coalescent, elongate and anteriorly slanted, dark markings on distal portion of each anal-fin pterygiophore. Dorsally and parallel to that line, long narrow band lacking dark chromatophores, forming white counterpart to it. Two vertical elongated fields, sometimes forming vertical bar, immediately anterior to base of caudal fin. Dorsal margin of caudal peduncle darker than surrounding areas. Head with uniform covering of fine chromatophores, densest on upper

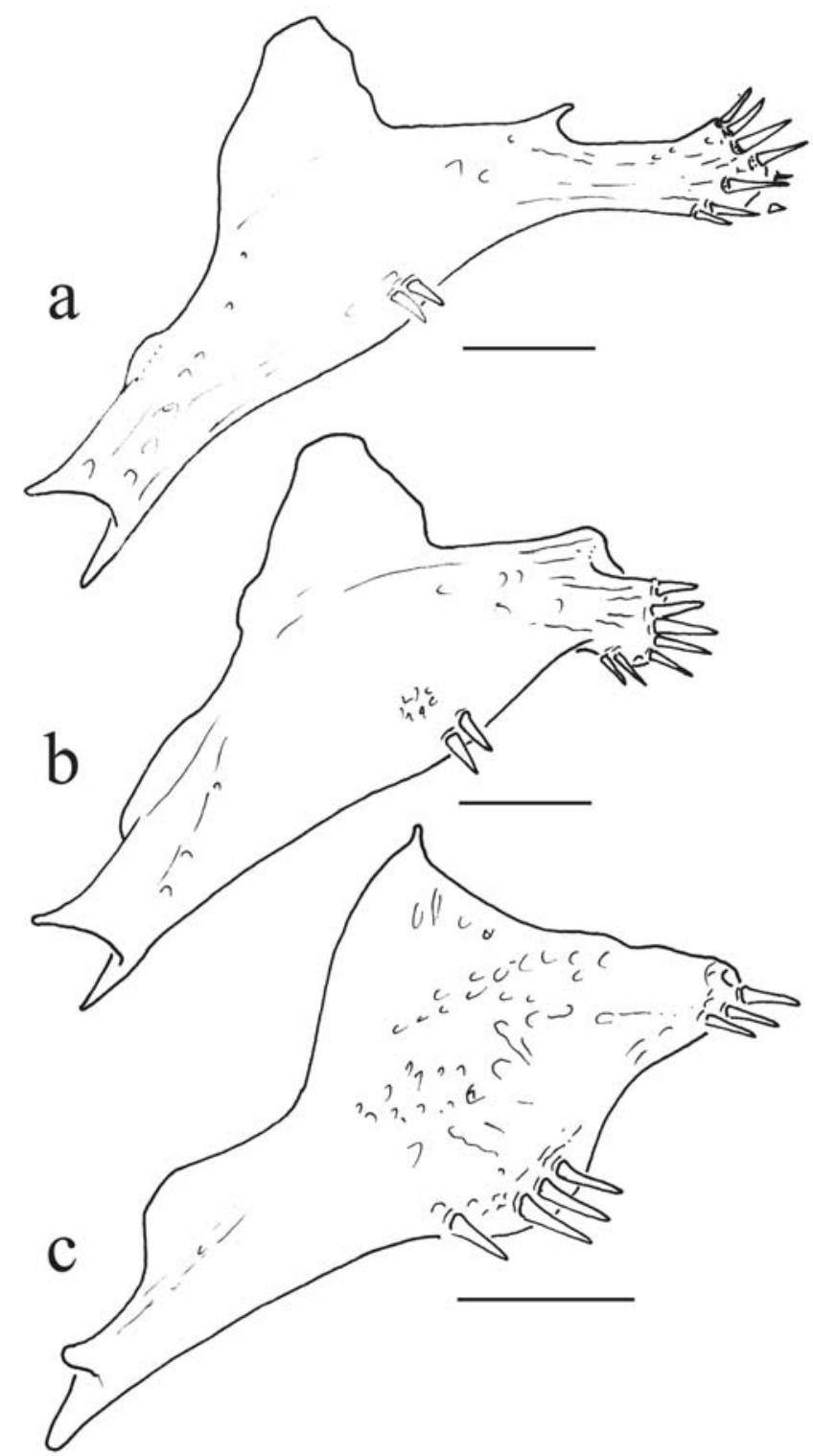

Fig. 6. Opercles of species of Trichogenes, lateral views, left sides. a) T. claviger, adult male, MZUSP 105732, paratype; b) T. claviger, adult female, MZUSP 105732; c) T. longipinnis, MZUSP 48108. Scale bars $=1 \mathrm{~mm}$. lip, nearly or totally lacking dark spots seen on body. Cheeks always lacking dark spots. Opercular process slightly darker than surrounding areas, its expanded tip with dark spot similar in color, shape and position to those on large series of spots on body. Small concentration of dark pigment on ventral patch of opercular odontodes. Integument amidst interopercular odontodes tinted with dark. Posterior naris white, surrounded by very dark rim. One or two temporal pores rimmed in dark. Nasal, maxillary and rictal barbels darkly-pigmented, with lighter cores. Nasal barbel darkest, except for its white basal narial tube. Maxillary barbel with dorsal surface darker than ventral. Rictal barbel lightest, with dark chromatophores at base and becoming progressively lighter distally. Ventral part of head with dark fields on region of lower jaw and margin of lower lip, with some scattered chromatophores also on branchial membranes. All fins with dark chromatophores alongside individual rays and segment limits, most pronouncedly along first pectoral-fin ray. Base of dorsal fin with irregular dark concentration. Base of caudal fin with welldefined semilunar dark field, apparently a continuation of the uniform background dark scattering on body.

The freshly-preserved specimens have a yellowish tint covering the dorsal part of head, including the infraorbital canal, the opercular process, the base of interopercular path of odontodes and most of the fins (Fig. 2). The opercular region dorsally to the interopercular patch of odontodes is pinkish due to branchial blood seen by transparency.

Sexual dimorphism. The degree of development of the posterior opercular process in $T$. claviger is sexually dimorphic. Specimens $36.6 \mathrm{~mm} \mathrm{SL}$ and larger fall into two well-defined classes with respect to the size of the process, large and small (Fig. 6a,b), with all specimens with the long process being males and all those with a short one, females. A total of 10 specimens were sexed (including $3 \mathrm{c} \&$ s ones), of which four were males and six females. The holotype was not directly sexed, but its long opercular process fits the morphology expected for males. In specimens $33.2 \mathrm{~mm}$ SL and smaller, no clear difference in proportional size of the opercular process was noticed. Both males and females have a dark spot at the tip of the opercular process and it is only the length of the latter which is sexually dimorphic. It is possible that the different lengths of the opercular process has a direct role in sexual signaling. Species of Trichogenes seem to be highly visually-oriented fish, and it has been shown experimentally that $T$. longipinnis will seek prey based on visual stimulus alone (Sazima, 2004). A black spot at the movable tip of a long opercular process is an obvious visual cue and, being sexually dimorphic, strongly suggests a sexual recognition function. A movable dark spot somewhere on the side of the body of the male is known to occur dimorphically also in other species of neotropical freshwater fish, such as in characids Corynopoma, Pseudocorynopoma and Pterobrycon. The spot-bearing anatomical structure varies among those taxa, and can be either modified opercular bones, the expanded tip of one or more pectoral-fin rays, or a hypertrophied scale, respectively (Bussing \& Roberts, 
1971), indicating that the strategy has evolved independently at least three times in glandulocaudines (N. Menezes, pers. comm.)

Distribution. Trichogenes claviger is known only from the type locality, an upland tributary of the headwaters of the rio Itapemirim drainage in southeastern Brazil (Fig. 7).

Ecological notes. The type series was collected in a shallow sector ( $\mathrm{ca} .30 \mathrm{~cm}$ ) of the córrego Picada Comprida (Fig. 8), on a plateau at $c a .1150 \mathrm{~m}$ altitude. The water is darkly tea-stained and transparent, with slow current and negligible altitudinal gradient. The stream runs through an area of moderately impacted high-altitude rainforest mingled with sectors of exotic pine culture. The substrate is mostly exposed sand, with masses of accumulated leaf litter and other vegetable debris in many spots. Fish were concentrated on quiet shaded areas with litter, swimming in midwater, and were collected with hand seines. No other fish species seems to co-occur with T. claviger. Preliminary observation of gut contents revealed numerous disarticulated arthropod remains, indicating that the feeding habits of the species are broadly similar to those of $T$. longipinnis. Specimens of the species were also observed swimming in two other nearby spots in tributaries to the córrego Picada Comprida, but were not seen in four additional collection points in the same stream system and their distribution seems to be patchy. The type locality is situated between two State Parks: Forno Grande and Pedra Azul, but lies outside of either, in private land. The exact geographical distribution of $T$. claviger is still undetermined, and more extensive fieldwork in the area will be necessary to obtain such information. In any event, it is certain that conservation measures will be needed to assure the survival of the species. The fact that $T$. claviger was discovered during a privately-commissioned environmental impact assessment demonstrates the importance of such initiatives for the knowledge of the freshwater fish fauna.

Etymology. Claviger means club-bearing in Latin, an allusion to the peculiar shape of the hypertrophied posterior process of the opercle in males of this species. An adjective.

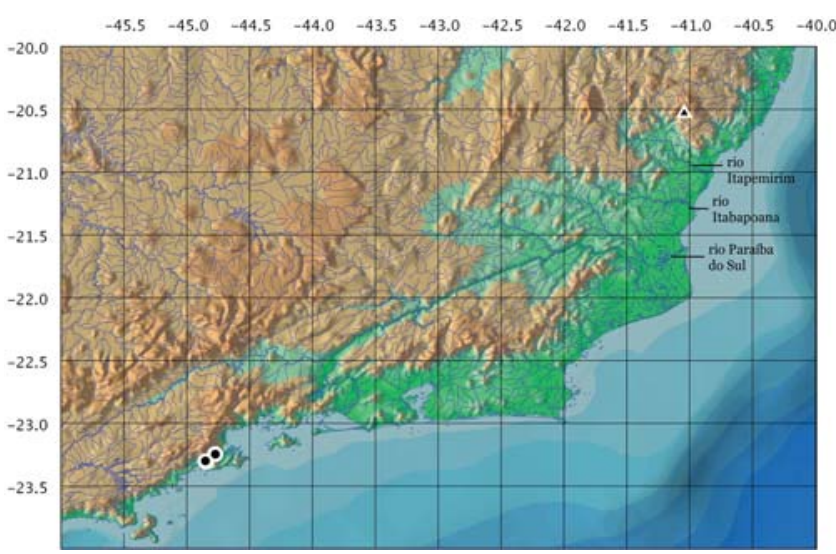

Fig. 7. Map of distribution of the species of Trichogenes: circle $=T$. longipinnis, triangle $=T$. claviger .
Remarks. The geographical ranges of T. longipinnis and of $T$. claviger are separated by approximately $500 \mathrm{~km}$ in straight line, and by several intervening independent drainages along the Atlantic coast. The two species probably have had a long history of isolation, as judging by the large set of distinguishing characteristics in external morphology and internal anatomy, summarized in the Diagnosis above. Some of the diagnostic characters deserve comment. Vertebral number seems to be a consistent meristic difference between the two species of Trichogenes, with a well-defined gap in counts. Interestingly, very limited variation was detected in the material examined, with $T$. longipinnis having $38(\mathrm{n}=9$, holotype) or $39(\mathrm{n}=5)$ vertebrae and all specimens of $T$. claviger with $35(n=18)$. The pattern of integumentary pigmentation in the two species of Trichogenes, although similar in general features, also consistently differ. Although much variation is seen among different populations of $T$. longipinnis (some of which is illustrated in Sazima, 2004), in no case does its pigmentation match the one in $T$. claviger. Part of the difference includes a dark line along the base of the anal fin of $T$. claviger. No such line is seen in $T$. longipinnis, although the distal portion of each of its pterygiophores appears as slightly darker than surrounding tissues due to the proximity of the bone to the surface of the skin. The resulting effect may look superficially similar to the dark line in T. claviger, but there is no dark pigment involved.

A single juvenile specimen of $T$. claviger has been collected so far (MBML 3290, $15.9 \mathrm{~mm} \mathrm{SL}$ ) and it displays some intriguing characteristics. The specimen has a very large eye, a compressed head, a very short snout, a prognathous mouth with the lower jaw produced and strongly oblique, and a markedly sloped anterior profile of the head (Fig. 9a). All those characteristics contrast with the situation in similarly-sized specimens of T. longipinnis, where the eye is comparatively small, the head is depressed, the snout is relatively long and the mouth is subterminal, with the lower jaw horizontal and included in the upper one, and the profile

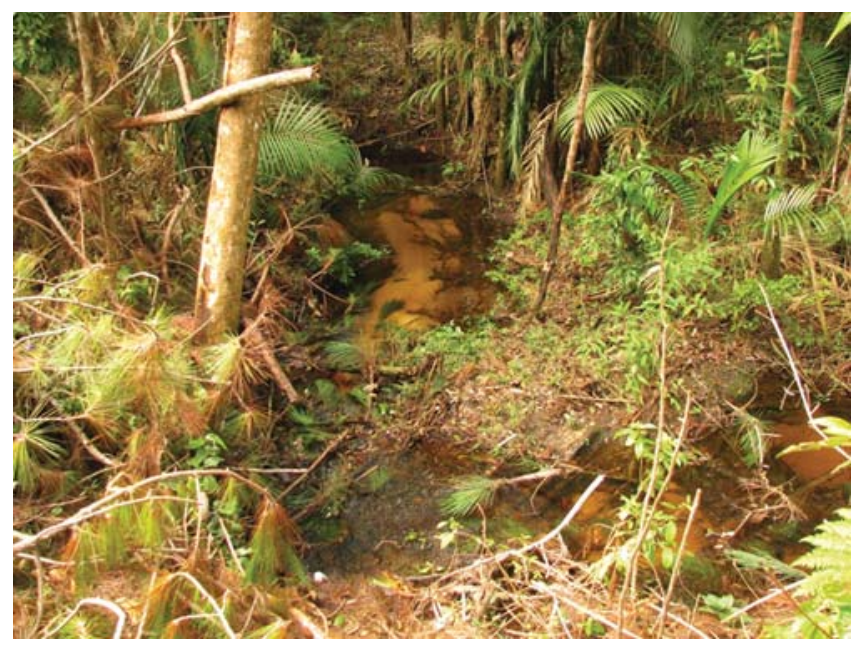

Fig. 8. General view of córrego Picada Comprida at site of collection of T. claviger. Photo by J. L. Helmer. 
Table 1. Morphometrics of Trichogenes claviger, $\mathrm{n}=18$, including holotype.

\begin{tabular}{lccccc}
\hline & Holotype & \multicolumn{2}{c}{ Range } & Mean & SD \\
\hline Standard length (mm) & 50.8 & 15.9 & 50.8 & - & - \\
& Percents of Standard length & & & \\
Body depth & 19.6 & 17.2 & 21.0 & 19.7 & 0.90 \\
Caudal peduncle depth & 11.5 & 9.3 & 11.5 & 10.4 & 0.66 \\
Head lenght & 22.9 & 19.7 & 23.9 & 22.4 & 1.25 \\
Pre-dorsal length & 67.7 & 64.1 & 72.0 & 66.8 & 2.17 \\
Pre-pelvic lengh & 41.7 & 38.9 & 45.4 & 42.4 & 1.78 \\
Dorsal-fin base & 9.0 & 7.9 & 11.6 & 9.5 & 1.06 \\
Pectoral-fin length & 17.1 & 13.2 & 18.9 & 16.6 & 1.31 \\
Pelvic-fin length & 9.9 & 7.5 & 10.9 & 9.7 & 0.73 \\
Anal-fin base & 43.2 & 40.2 & 49.8 & 44.3 & 1.90 \\
Body width & 18.9 & 13.5 & 19.5 & 17.4 & 1.50 \\
& 17.9 & 17.9 & 38.1 & 25.3 & 5.36 \\
Orbital diameter & 52.8 & 33.9 & 56.8 & 44.7 & 6.38 \\
Snout length & 51.5 & 44.6 & 59.7 & 50.1 & 3.66 \\
Interorbital width & 50.1 & 43.2 & 56.7 & 49.1 & 3.43 \\
Mouth width & & & &
\end{tabular}

of the head is gently sloped (Fig. 9b). Evidently, juveniles of $T$. longipinnis are more similar to their respective adults than young of $T$. claviger to theirs. Juveniles of Copionodontinae (cf. Campanario \& de Pinna, 2000; pers. obs.) and at least some Trichomycterinae ( $c f$. Lundberg et al., 2004) also do not differ markedly from their respective adults. The morphology of young T. claviger is thus deviant amidst its immediate phylogenetic neighbors, and is most likely an autapomorphic modification of the juvenile stage of the species. Of course, few juveniles of Trichomycteridae have been described and this hypothesis awaits confirmation. In any event, the young stage of $T$. claviger differs markedly from those of Siluriformes in general (cf. Nakatami et al., 2001; Lundberg et al., 2004; Leite et al., 2007). The quite distinct head and mouth morphologies also suggest different juvenile ecologies. Young and mid-sized specimens of T. longipinnis have been shown to be preferential daytime foragers and visually-oriented towards food items (Sazima, 2004). It seems likely that such traits will also be present in $T$. claviger, perhaps even more pronounced. It is also expected that their feeding behavior will be more strongly directed towards surface- and midwaterpicking. Sazima (2004) suggested that T. longipinnis, at least while juvenile and mid-sized, partly play the ecological role of a tetra (species of Astyanax and related small characins), i.e., diurnal, nektonic and insectivorous. This idea is supported by the apparent competitive exclusion of $T$. longipinnis and Astyanax spp., the latter present throughout the general area of distribution of the former, but locally absent in its exclusive steep stream sectors. The physical stream characteristics have been proposed as a barrier preventing the establishment of Astyanax populations in T. longipinnis localities (Sazima, 2004). The more characin-like morphology (and putatively, habits) of $T$. claviger, especially as a juvenile, suggests a similar history of association with characin-free habitats. However, the environment of the new species is not steep water courses as that of its congener, but rather slow sectors of streams with little altitudinal gradient. It is not yet known which factors have kept species of Astyanax and other fish from entering the habitat of $T$. claviger.

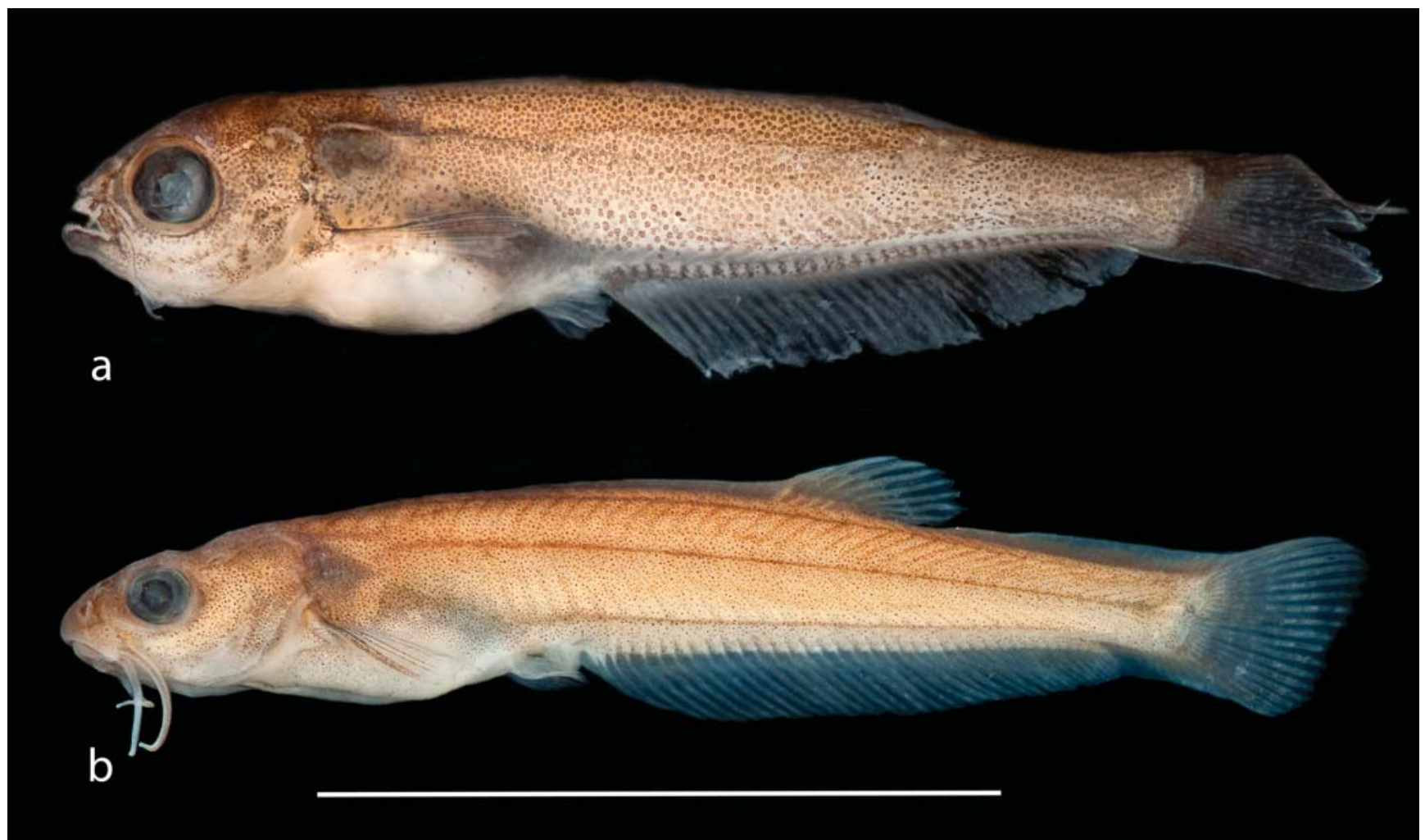

Fig. 9. Comparison of juvenile specimens of Trichogenes. a) T. claviger, MBML 3290, paratype, 15.9 mm SL; b) T. longipinnis, MZUSP 80933, $16.5 \mathrm{~mm}$ SL. Scale bar $=10 \mathrm{~mm}$ SL. Photos by V. Barão. 


\section{Discussion}

There is overwhelming evidence that Trichogenes claviger is the closest relative of $T$. longipinnis, and that the genus Trichogenes including both species is monophyletic. The most evident synapomorphy for the genus is the uniquely long anal fin, with 30-38 segmented rays (associated with 32-35 pterygiophores). Elsewhere in trichomycterids, the longest anal fins are seen in members of the subfamily Tridentinae, with 15 to 22 anal-fin rays, a trait considered a synapomorphy for the group (Baskin, 1973) but evidently convergent with the condition in Trichogenes in view of the phylogenetic distance between the two taxa ( $c f$. de Pinna, 1998). The usual anal-fin ray count in trichomycterids is $8-12$, also seen in more distant outgroup loricarioids such as Nematogenyidae. The structure of the pelvic-fin skeleton in the two species of Trichogenes is also unique among trichomycterids. The basipterygium in both $T$. longipinnis and $T$. claviger is modified into a large quadrangular or pentagonal plate, with the inner arm incorporated into the main body of the bone, and the external one stout and pointed, directed straight anteriorly. This morphology is markedly different from the relatively small basipterygium with two divergent thin arms anteriorly, seen in all other trichomycterids and in their closest relative Nematogenyidae, as well as in the majority of other catfishes. Another synapomorphy for Trichogenes is found in the structure of the lateral portion of the skull. In both species of the genus, the margin of the frontal between the sphenotic and the lateral ethmoid is expanded into a large shelf, forming a continuous bony platform around the dorsal margin of the eye. No such expansion is seen in other members of the Trichomycteridae, although in Copionodontinae there are sometimes small irregular lateral outgrowths of the frontal. Such condition may be a less extreme homologue to the complete shelf in Trichogenes, but resolution of this question will have to await more detailed studies. Less decisive evidence, whose significance depends on specific character interpretations, also exists for the monophyly of Trichogenes. The presence of two separate patches of odontodes on the opercle is unique to the genus among trichomycterids (Fig. 6), which otherwise have a single patch corresponding to the dorsal patch in Trichogenes. While the extra ventral odontode patch may be an additional synapomorphy for the genus, it is also possible that such state is intermediate between that in outgroup loricarioids and the one in remaining trichomycterids. In the former, odontodes are more or less widely distributed over the surface of the bone, while in the latter they are restricted to a well-defined patch at the tip of a specialized bony process. The situation in Trichogenes might be a phylogenetically intermediate stage where odontodes are halfway to disappearing from all the rest of the bone except for the posterior process. In that case, the condition in Trichogenes would not be synapomorphic. Notwithstanding, independent evidence discussed above still robustly supports the monophyly of Trichogenes.
Character conditions in T. claviger fully agree with current hypothesis about lower trichomycterid relationships, where most of the family is united into a large monophyletic group excluding only Trichogeninae and Copionodontinae (de Pinna, 1998; Datovo \& Bockmann, 2010). Synapomorphies for that clade include a fusion among the pterotic, sphenotic and pterosphenoid; loss of the intercalarium as one of the Weberian ossicles (but this may need reevaluation, as an intercalarium seems to be present in some basal trichomycterines as well; de Pinna \& do Nascimiento, pers. obs.); loss of most of the infraorbital and preopercular branches of the laterosensory canal system; loss of the interhyal; reduction of the lateral opening of the swimbladder capsule; loss of the ductus pneumaticus; five or fewer pelvicfin rays; presence of a protractor operculi muscle; and fibers of the levator operculi posterodorsally-directed towards its origin (Baskin, 1973; de Pinna, 1992; de Pinna, 1998; Datovo \& Bockmann, 2010). Trichogenes claviger, like T. longipinnis and copionodontines, lacks all those derived conditions and does not seem to add any homoplasy to that particular region of the trichomycterid tree.

In other issues, however, character conditions in $T$. claviger bring new questions to the fore. For example, the presence of odontodes on the dorsal margin of the interopercle (Fig. 4), supported by a special bone expansion, is very similar and probably homologous to a condition previously interpreted as a synapomorphy for copionodontines (de Pinna, 1992). It is now uncertain whether such character is a synapomorphy for copionodontines convergent in $T$. claviger, or a synapomorphy for Trichogeninae plus Copionodontinae, lost in T. longipinnis. The latter hypothesis is more likely, because some specimens of $T$. longipinnis have a few small slanted odontodes on the dorsoposterior part of the interopercle, clearly an incipient condition of the derived state. On a similar theme, the tooth structure of $T$. claviger, simultaneously spatulate and bifurcated (Fig. 5), is clearly intermediate between the simple spatulate condition in copionodontines and the conical bifurcated teeth in $T$. longipinnis ( $c f$. de Pinna, 1998: fig. 5). Such character conditions in T. claviger provide further, if indirect, support for a hypothesis of Copionodontinae and Trichogeninae as sister-groups, already suggested by a number of other characters (de Pinna, 1998; Bichuette et al., 2008).

A more puzzling observation is the presence of extensive distal bifurcation in the neural spines of the anterior four vertebrae in T. claviger (Fig. 3a). This is a plesiomorphic condition often associated with the dorsal-fin spine mechanism normally seen in catfishes, but otherwise entirely lost in Trichomycteridae, where all neural spines are unbranched or only incipiently branched (Baskin, 1973: 46). No hint of bifurcation is seen in the neural spines of $T$. longipinnis (Fig. 3b). The Nematogenyidae also lack a dorsalfin spine locking mechanism, but retain bifurcated anterior neural spines. The bifurcated condition in $T$. claviger is unique in the Trichomycteridae, and difficult to interpret within present knowledge of relationships in the group. The character 
is parsimoniously mapped with two simple steps: loss of the bifurcation at the base of Trichomycteridae, and a reversal in $T$. claviger. However, it is difficult to understand a reversal to a bifurcated condition without any associated reversals also in the dorsal-fin spine locking mechanism, which in T. claviger is as absent as in all the rest of the family. Perhaps the bifurcation is instead somehow associated with the autapomorphic presence of a median claw-like process in the neural arches of the anterior four vertebrae seen in T. claviger (Fig. 3a; see below). Since the vertebrae bearing the bifurcation are the same ones bearing the claw-like process, the possibility of an alternative functional association for bifurcated neural spines is compelling. Both the bifurcation and the process probably represent reinforced attachments of the dorsal trunk musculature onto the vertebral column, in turn perhaps associated with a pelagic life and midwater or surface feeding of the species. A comparative study of the myology associated with the anterior neural spine complex in $T$. claviger, as well as knowledge on details of its swimming and feeding mode, may help to resolve the question.

Autapomorphies for T. claviger include its terminal mouth, a unique case among trichomycterids, which have subterminal or inferior mouths (Fig. 1). Also autapomorphic and unique in the family is the presence of a large median claw-like anterodorsal process on the neural arch of the four anterior free vertebrae (Fig. 3a). This process, together with the distally split neural spine, forms a conspicuous tripartite structure on the dorsal part of the neural arch of the four anterior vertebrae. An additional autapomorphic character is the sexually dimorphic posterior process of the opercle (Fig. 6; see Sexual dimorphism, above), the first record of secondary sexual dimorphism in the family. Finally, the peculiar juvenile morphology of $T$. claviger, with a prognathous oblique mouth, compressed head, and a steeply sloped anterior profile of the skull (Fig. 9a; see Remarks above), seems to constitute a case of autapomorphic larval specialization.

Comparative material. All from Brazil: Copionodon lianae: MZUSP 81034, holotype, $45.9 \mathrm{~mm} \mathrm{SL}$, Bahia, rio Grisante (rio Mucujê drainage). Copionodon orthiocarinatus: MZUSP 42463, holotype, 37.7 mm SL, Bahia, Mucujê, rio Mucujê; MZUSP 42464, 2 (1 c\&s), paratypes, 29.2-30.1 mm SL, collected with holotype; MZUSP 100723, 58, 23.3-68.5 mm SL, Bahia, Guiné, upper rio Preto (south vertent), approximately at latitude of the town of Guiné. Copionodon pecten: MZUSP 42461, holotype, $59.8 \mathrm{~mm}$ SL, Bahia, Mucujê, rio Mucujê; MZUSP 42462 , 33 (5 c\&s), paratypes, 31.4-62.2 $\mathrm{mm} \mathrm{SL}$, collected with holotype; MZUSP 100710, 22, 13.5-54.4 mm SL, Bahia, Andaraí, rio Coisa Boa, at road to Igatu. Copionodon sp.: MZUSP 89584, 8 (2c\&s), 33.8-55.1 $\mathrm{mm}$ SL, Bahia, Itaetê, rio Barrigudinha (tributary to rio Una). Glaphyropoma rodriguesi: MZUSP 42465, holotype, $50.7 \mathrm{~mm}$ SL, Bahia, Mucujê, rio Mucujê; MZUSP 42466, 13 (2 c\&s), paratypes, 28.8-45.4 mm SL, collected with holotype; MZUSP 93266, 1, $17.3 \mathrm{~mm}$ SL, Bahia, Mucujê, rio Piabas, near road AndaraíMucujê. Trichogenes longipinnis: MZUSP 16099, holotype; 64.0 mm SL, Cachoeira do Amor, km 3 of Parati-Ubatuba road, São Paulo; MZUSP 16106, 1 (c\&s, disarticulated), paratype, collected with holotype; MZUSP 16107, 1, paratype, $52.4 \mathrm{~mm} \mathrm{SL}$, collected with holotype; MZUSP 16108, 1, paratype, $52.5 \mathrm{~mm} \mathrm{SL}$, collected with holotype; MZUSP 16109, 1 (c\&s, disarticulated), paratype, collected with holotype; MZUSP 16110, 1, paratype, $49.7 \mathrm{~mm}$ SL, collected with holotype; MZUSP 16111, 1, paratype, $45.0 \mathrm{~mm} \mathrm{SL}$, collected with holotype; MZUSP 16112, 1, paratype, $41.1 \mathrm{~mm} \mathrm{SL}$, collected with holotype; MZUSP 16113, 1, paratype, $34.1 \mathrm{~mm} \mathrm{SL}$, collected with holotype; MZUSP 16114, 1, paratype, $31.7 \mathrm{~mm} \mathrm{SL}$, collected with holotype; MZUSP 40238, 9 (2 c\&s), 47.9-125.8 $\mathrm{mm}$ SL, São Paulo, Ubatuba, Cachoeira do Amor, $3 \mathrm{~km}$ from State limit Rio de Janeiro-São Paulo; MZUSP 48108, 6 (3 c\&s), 41.1$114.3 \mathrm{~mm}$ SL, Rio de Janeiro, Parati, rio Parati-Mirim; MZUSP 80933, 10, 10.7-21.6 mm SL, São Paulo, Ubatuba, creek ca. $500 \mathrm{~m}$ after km 3 of Rio-Santos road; MZUSP 83451, 23 (1 c\&s), 12.8$74.7 \mathrm{~mm}$ SL, São Paulo, Ubatuba, rio do Bagre, Parque Estadual da Serra do Mar, km 0.5 of Rio-Santos road, 2321'13'S 4446'08'W; MZUSP 83455, 1 (c\&s), ca.75 mm SL, São Paulo, Ubatuba, Parque Estadual da Serra do Mar, Núcleo Picinguaba, km 1 of Rio-Santos road, rio Camburi, Cachoeira da Escada, upstream from road; MZUSP 83456, 11 (1 c\&s), 11.5-65.6 mm SL, São Paulo, Ubatuba, Piscina do Amor, km 3 of Rio-Santos road.

\section{Acknowledgements}

We thank Makoto Meio Ambiente Sustentabilidade Ltda for logistic support and BRASIF S.A. Administrações e Participações for allowing access to do fieldwork in their property. Collecting was done under IBAMA permit No 16/2009-NUPESCA/ DIPRAM/ES (Process 02009.001088/2009-79). For help in field work, we are grateful to L. Son, J. F. Targa, J. E. Simon, R. L. Martins and J. Peres. Research funding was provided by CNPq (Conselho Nacional de Desenvolvimento Científico e Tecnológico) and FAPESP (Fundação de Amparo à Pesquisa do Estado de São Paulo). Vitor Barão edited the photographs and André Netto-Ferreira helped with the map. The manuscript benefited from suggestions by two anonymous referees and from a particularly thorough review by F. A. Bockmann.

\section{Literature Cited}

Baskin, J. N. 1973. Structure and relationships of the Trichomycteridae. Doctoral Dissertation, City University of New York, New York, USA, 389p.

Bichuette, M. E., M. C. C. de Pinna \& E. Trajano. 2008. A new species of Glaphyropoma: the first subterranean copionodontine catfish and the first occurrence of opercular odontodes in the subfamily (Siluriformes: Trichomycteridae). Neotropical Ichthyology, 6(3): 301-306.

Britski, H. A. \& H. Ortega. 1983. Trichogenes longipinnis, novo gênero e espécie de Trichomycterinae do sudeste do Brasil. Revista Brasileira de Zoologia, 1(3): 211-216.

Bussing, W.A. \& T. R. Roberts. 1971. Rediscovery of the glandulocaudine fish Pterobrycon and hypothetical significance of its spectacular humeral scales (Pisces: Characidae). Copeia, 1971: 179-181.

Datovo, A. \& F. A. Bockmann. 2010. Dorsolateral head muscles of the catfish families Nematogenyidae and Trichomycteridae (Siluriformes: Loricarioidei): comparative anatomy and phylogenetic analysis. Neotropical Ichthyology, 8(2): 193-246.

Leite, R. G., C. Cañas, B. Forsberg, R. Barthem \& M. Goulding. 2007. Larvas dos grandes bagres migradores. Manaus, Instituto Nacional de Pesquisas da Amazônia/Asociación para la Conservación de la Cuenca Amazónica, 127p. 
Lundberg, J. G., T. M. Berra \& J. P. Friel. 2004. First description of small juveniles of the primitive catfish Diplomystes (Siluriformes: Diplomystidae). Ichthyological Exploration of Freshwaters, 15(1): 71-82.

Nakatami, K., A. A. Agostinho, G. Baumgartner, A. Bialetzki, P. V. Sanches, M. C. Makrakis \& C. S. Pavanelli. 2001. Ovos e larvas de peixes de água doce: desenvolvimento e manual de identificação. Maringá, Eduem, 378p.

de Pinna, M. C. C. 1992. A new subfamily of Trichomycteridae (Teleostei: Siluriformes), lower loricarioid relationships and a discussion on the impact of additional taxa for phylogenetic analysis. Zoological Journal of the Linnean Society, 106(3): 175-229.

de Pinna, M. C. C. 1998. Phylogenetic relationships of neotropical Siluriformes (Teleostei: Ostariophysi): historical overview and synthesis of hypotheses. Pp. 279-330. In: Malabarba, L. R., R. E. Reis, R. P. Vari, Z. M. S. Lucena \& C. A. S. Lucena (Eds.). Phylogeny and Classification of Neotropical Fishes. Porto Alegre, Edipucrs, 603p.

Sazima, I. 2004. Natural history of Trichogenes longipinnis, a threatened trichomycterid catfish endemic to Atlantic forest streams in southeast Brazil. Ichthyological Exploration of Freshwaters, 15(1): 49-60.

Sazima, I. 2008. Trichogenes longipinnis Britski \& Ortega, 1983. Pp. 249-250. In: Machado, A. B. M., G. M. Drummond \& A. P. Paglia (Eds.). Livro Vermelho da Fauna Brasileira Ameaçada de Extinção. Brasília/Belo Horizonte, Ministério do Meio Ambiente/ Fundação Biodiversitas, 1420p.

Song, J. \& L. R. Parenti. 1995. Clearing and staining whole fish specimens for simultaneous demonstration of bone, cartilage and nerves. Copeia, 1995:114-118.

Stiassny, M. J. L. \& M. C. C. de Pinna. 1994. Basal taxa and the role of cladistic patterns in the evaluation of conservation priorities: a view from freshwater. Pp. 235-249. In: Forey, P. L., C. J. Humphries \& R. I. Vane-Wright (Eds.). Systematics and Conservation Evaluation. Systematics Association Special Volume no. 50. Oxford, Clarendon Press.

Tchernavin, V. V. 1944. A revision of some Trichomycterinae based on material preserved in the British Museum (Natural History). Proceeding of the Zoological Society of London, 114: 234-275.

Taylor, W. R. \& G. C. van Dyke. 1985. Revised procedures for staining and clearing small fishes and other vertebrates for bone and cartilage study. Cybium, 9(2): 107-119.

Zamudio, K. R., J. M. Robertson, L. M. Chan \& I. Sazima. 2009. Population structure in the catfish Trichogenes longipinnis: drift offset by asymmetrical migration in a tiny geographic range. Biological Journal of the Linnean Society, 97(2): 259-274.

Accepted September 7, 2010

Published December 16, 2010 